\title{
DETECTION OF SPECIFIC ANTIBODIES AGAINST NEWCASTLE DISEASE IN THE EGG YOLK OF DIFFERENT TYPES OF CHICKS AND BIRDS
}

\author{
A.Z. ALZUBEADY; A. TAHA and A.A.K. SHEEHAN \\ Department of Microbiology, College of Veterinary Medicine, University of Mosul, Mosul, Iraq \\ Email: abd.imt74@yahoo.com
}

\section{ABSTRACT}

Received at: $20 / 1 / 2014$

This study was aimed to detection of specific antibodies against Newcastle disease in the egg yolk of different types of chicks and birds, Five samples of eggs were obtained from each of local breed chicks, House breeding (Al-Arab) chicks, ducks, pigeon birds, in addition to hatching birds of broiler, Yolk was separated and diluted in distal water $(1: 1)$ and divided in to two parts: First part was used to evaluate the

Accepted: $27 / 3 / 2014$ specific antibodies against Newcastle disease in the egg yolk whereas second part was used as an attemption to elevate levels of protection against ND in small chicks at 28 days old by i.m injection of diluted yolk extract at a dose of $0.5 \mathrm{ml}$, Thirty chicks classified into six groups was used for this purpose, each group was injected by type of diluted yolk extract of different eggs and last group kept as control group without any treatment, Levels of specific antibodies against ND in egg yolk and serum of injected chicks with diluted yolk were tested by Heamagglutination inhibition test using $4 \mathrm{HA}$ for live attenuated ND virus (lasota). Results were showed that highest titer of specific antibodies against ND was in the yolk of hatching eggs at a level of (32) whereas the lower titer was in the yolk of Duck eggs at a level of (2.6), Whereas the highest titer of injected chicks by yolk extract was in the first group which injected by yolk extract of hatching eggs at a level of (19.2) and lower titer was in group of chicks which injected by yolk extract of Duck egg at a level of (2.2).

Key words: Specific A.b., Newcastle Disease, Egg yolk, Chicks.

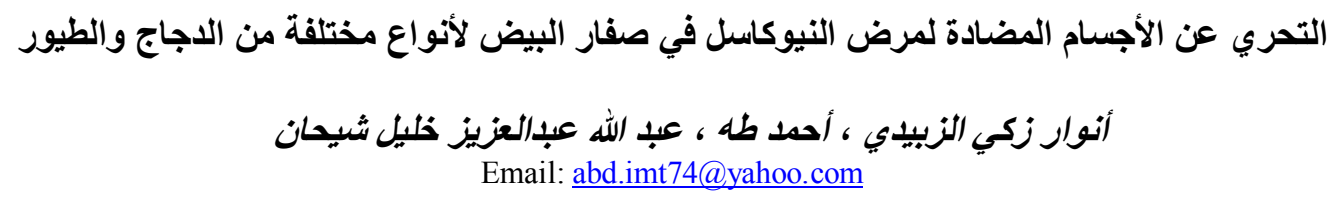

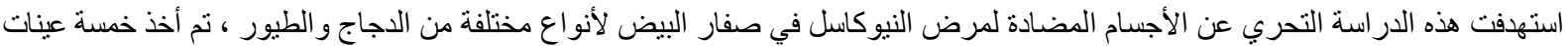

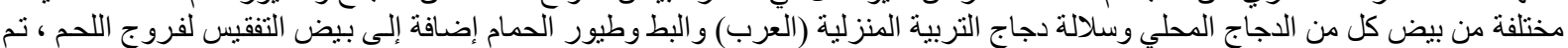

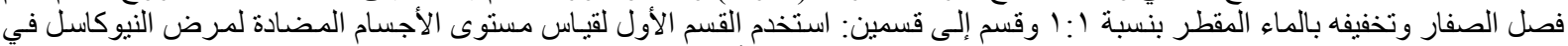

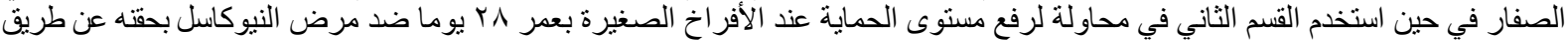

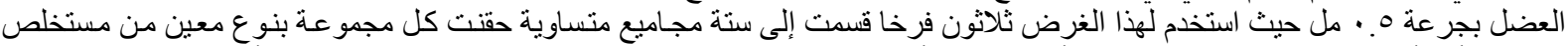

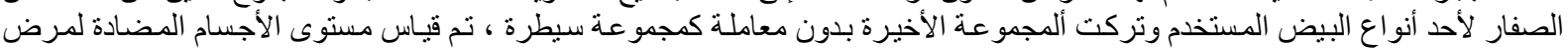

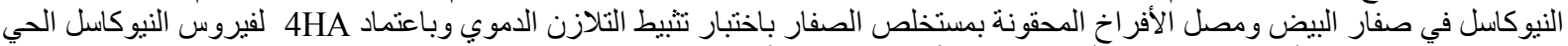

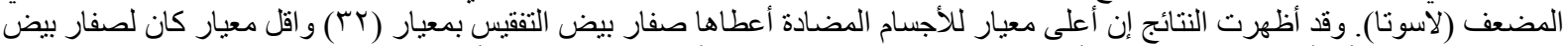

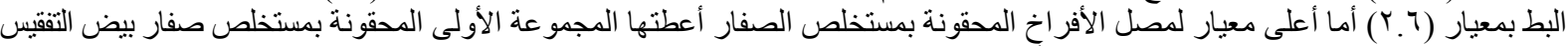

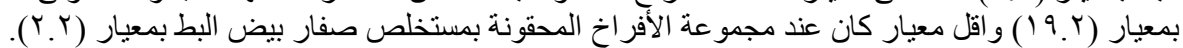

\section{INTRODUCTION}

$$
\text { المقدمـــة }
$$

يعد مرض النيوكاسل في الدو اجن من الأمر اض الفايروسية الوبائية الخطيرة على صناعة الدو اجن في العالم وذللك من خلال مـا يسببه من خسائر

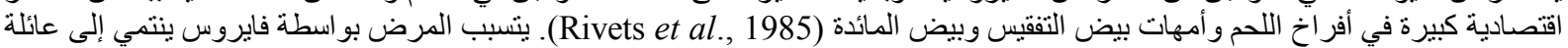

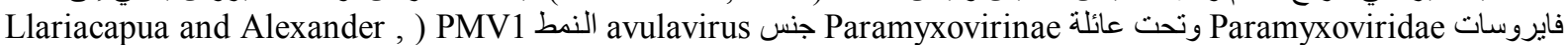

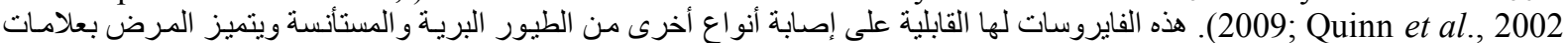

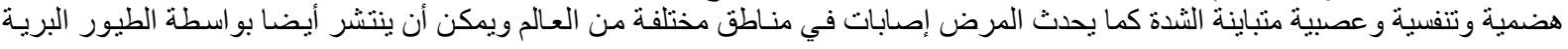




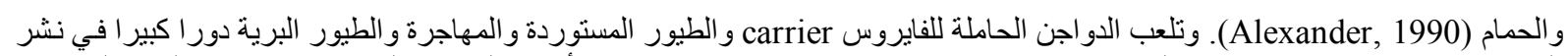

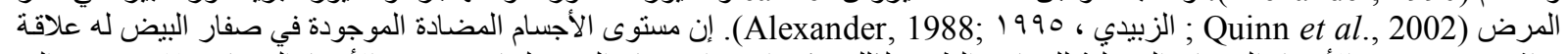

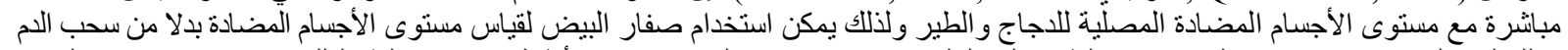

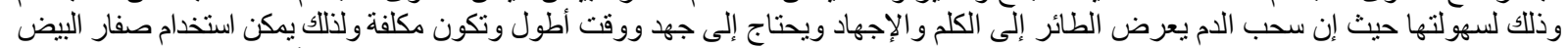

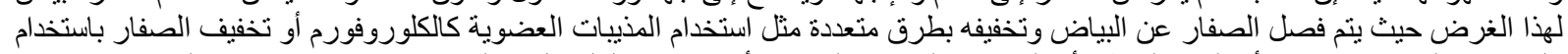

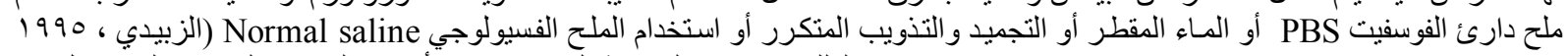
(Rudiger and Straughan, 1996; Alexander, 2003;

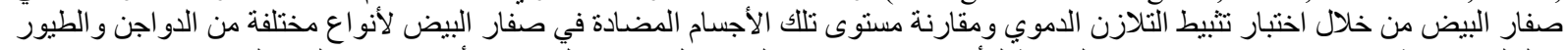

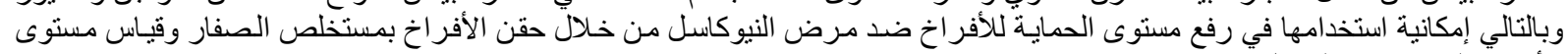

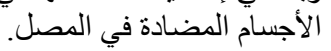

\title{
MATERIALS and METHODS مواد وطر ائق العمل
}

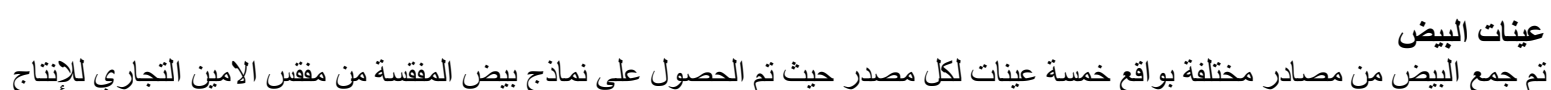

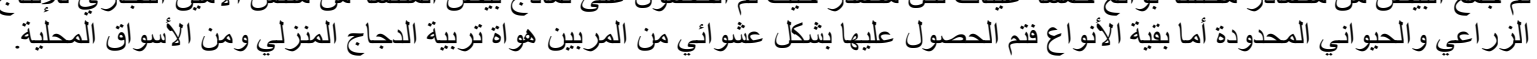

الأفراخ

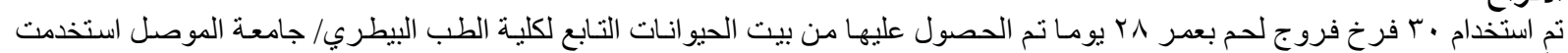
لأغر اض حقن مستخلص صفار البيض وبو اقع ه. • مل في العضل/ طائر وقسمت إلى خمسة مجاميع:

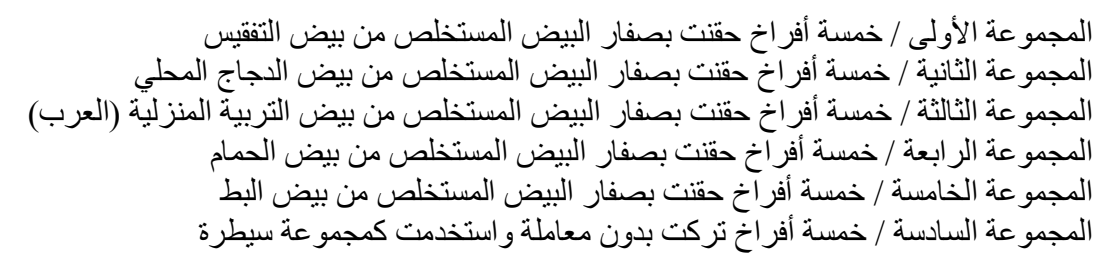

عينات المصل

جمعع الدم من مجاميع الأفراخ بعد خمسة أيام من عملية حقن مستخلص صفار البيض ومن القلب مباشرة ومن دون استخدام موانع التخثر وتم فصل المصل وحفظ تحت التجميد لحين استعماله في الاختبار المصلي.

عترة الفيروس

استخدمت عترة اللقاح الحي المضعف (لاسوتا) EID 50 شركة لو همان في اختبار التلازن الدموي.

الستخلح الفسيولوجي الفبيولو جي الجاهز المتو فر في الأسو اق في كل من اختبار النتلازن الدموي لتخفيف عترة اللقاح (لاسوتا) وفي عملية غسل خلايا الدم

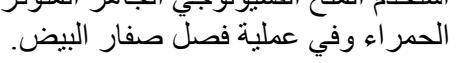

خلايا الام الحمراء المغسولة

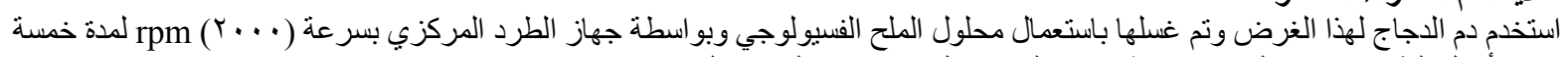
دقائق أهمل الطافي وخفق الراسب بنسبة (1\%) للاستعمال في أختبار الثنلازن الدموي.

فصل صفار البيض

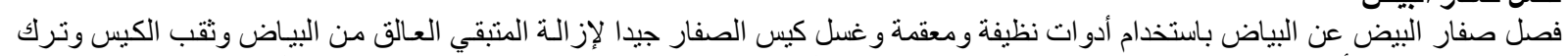

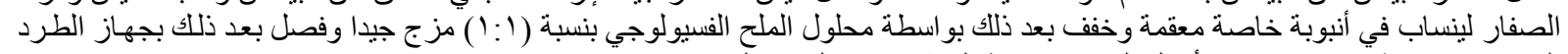

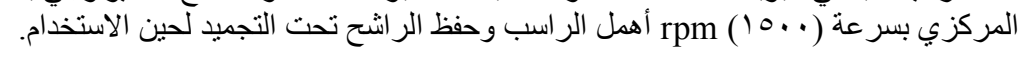

الفحوصات المستخدمة الفتازي

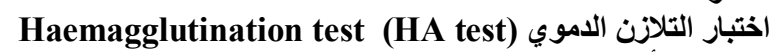

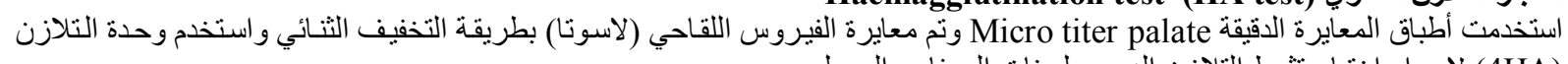

(4HA)

اختبار تثبيط التلازن الدموي Haemagglutination Inhibition test (HI test)

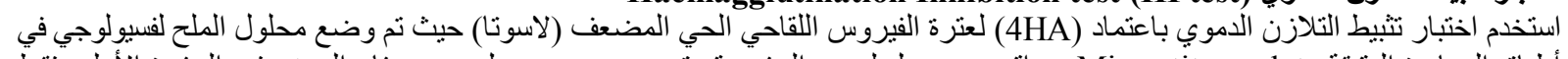

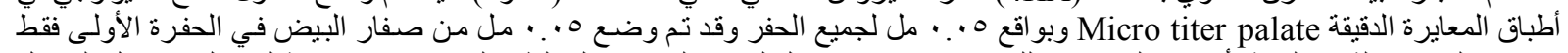

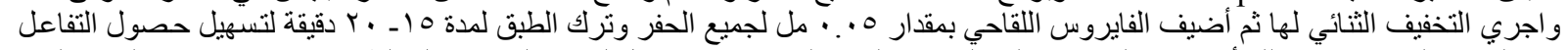

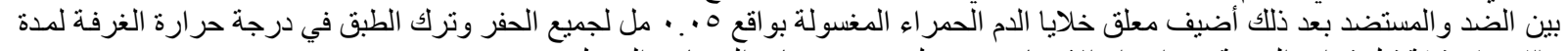

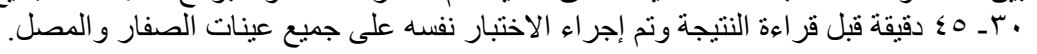




\section{RESULTS \\ النتائَج}

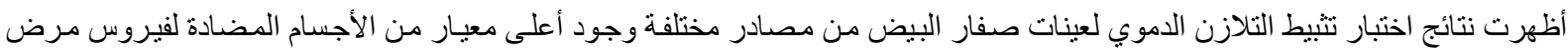

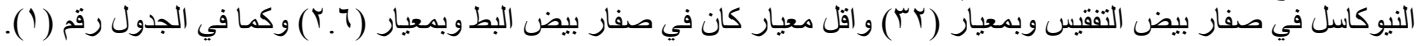

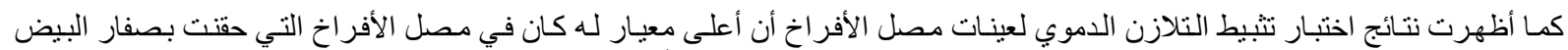

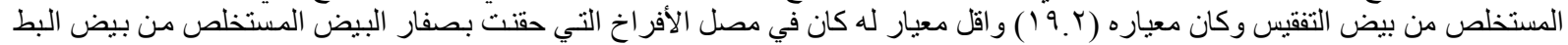

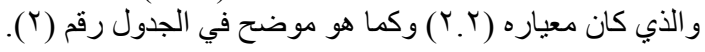

جدول رقم 1: معدل معيار الأجسام المضادة لفيروس النيوكاسل في صفار البيض في اختبار تثبيط التنازن الدموي.

\begin{tabular}{|c|c|}
\hline معدل معيار تثبيط التلازن الدموي & نوع البيض \\
\hline Tr & بيض التفقيس \\
\hline 17 & بيض الدجاج المحلي \\
\hline$\varepsilon$ & بيض التربية المنزلية ( العرب) \\
\hline$\varepsilon .1$ & بيض الحمام \\
\hline$r .7$ & بيض البط \\
\hline
\end{tabular}

جدول رقم ا: معدل معيار الأجسام المضادة لفيروس النيوكاسل في مصل الأفر اخ التي حقتت بأنواع مختلفة من مستخلص صفار البيض في اختبار تثبيط التلازن الدموي.

\begin{tabular}{|c|c|}
\hline متوسط معيار تثبيط التلازن الدموي & 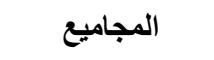 \\
\hline 19.4 & المجموعة الأولى \\
\hline$\Lambda . r$ & المجمو عة الثانية \\
\hline$r .7$ & المجمو عة الثالثة \\
\hline$\varepsilon .1$ & المجمو عة الر ابعة \\
\hline r.r & المجمو عة الخامسة \\
\hline $1 . \varepsilon$ & المجمو عة السادسة \\
\hline
\end{tabular}

\section{DISCUSSION \\ المناقشة}

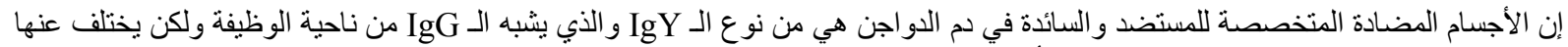

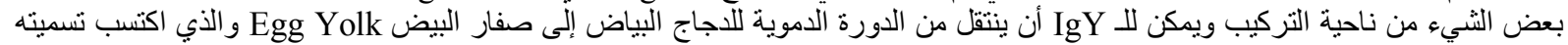

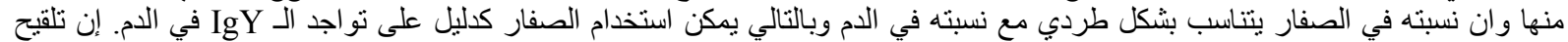

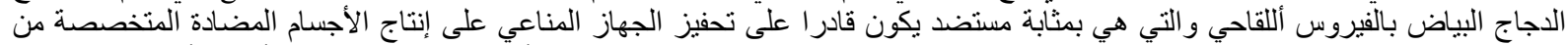

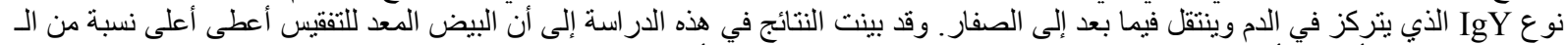
مقارنة مع الأنواع ألأخرى من عينات البيض و السبب في ذللك يعود إلى إن أمهات بيض التئ التفقيس Parent stocks

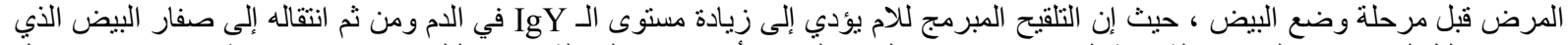

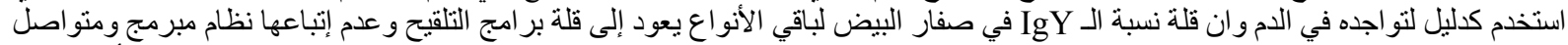

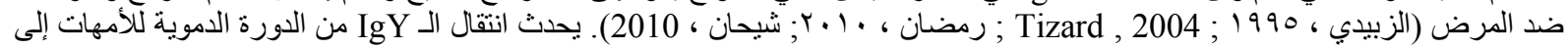

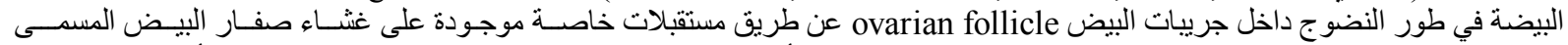
IgY receptors on ovarian follicles and Orlans , 1981 والخطوة الثانية انتقال الـ IgY من صفار البيض egg yolk إلى ألصوص عن طريق دوران الدم في المرحلة الجنينية إعmbryonic circulation إعطاءه كمناعة جاهزة منفعلة passive immunity و هي من التوجهات الحديثة في استخدام الـ IgY كتطبيق علاجي للسيطرة على العديد من 


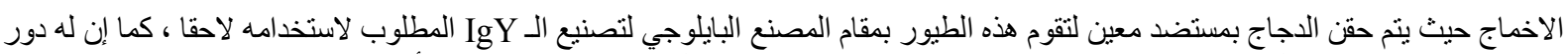

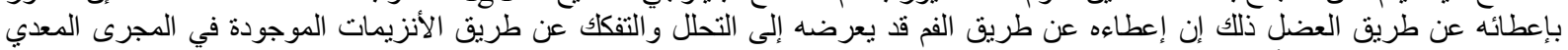

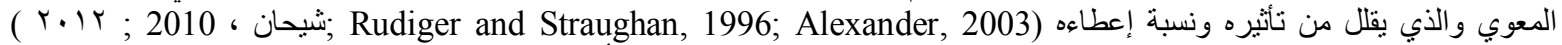
Alzubeady and Alattar, كثير من الاخماج ولكن بأسلوب علمي مدروس لإنجاح عملية تطبيقه.

\section{REFERENCES \\ المراجـع}

Alexander, D.J. (1988): Newcastle disease. Kulwer Acad. Pubsbosten.

Alexander, D.J. (1990): Avian Paramyxo viridae. Recent development Vet. Microbiol. 23:3-114.

Alexander, D.J. (2003): Newcastle disease. In: Diseases of poultry CY.M.SA. F, edj. 11th Ed Iowa state university press, Ames, 64-87.

Alzubeady, A.Z. and Alattar, M.Y. (2012): Effect of hyper immunized egg yolk on maternal immunity of Newcastle disease vaccine in broiler chicks. Accepted research in 6th conference of Vet. Med. College of Mosul in No. 393. 2012.

IANR, Tizard (2004): Veterinary Immunology An Introduction. seventh ED. Elsevier (USA).

Llariacapua and D.J. Alexander (2009): Avian Influenza and Newcastle disease. Springer. Verlag, Italia: 19-24.

Quinn, P.J.; Markwy, B.K.; Carter, M.E.; Donnelly, W.J.C. and Leonard, F.C. (2002): Veterinary Microbiology and Microbiol; Black well publishing company, UK.

Rivets, B.; Weisman, Y.; Herband, M.R. and Herzberg, M. (1985): Evaluation of a novel rapid kit for vistual detection of Newcastle disease virus antibodies. Avi. Dis. 29(4): 929-942.

Rose, M.E. and Orlans, E. (1981): Immunoglobulins in the egg embryo, and young chick. Dev. Comp. Immunol., 5, 15-20.

Rudiger, S. and Straughan, D. (1996): The production of Avian (Egg Yolk) Antibodies: IgY, ATLA 24, 925-934.

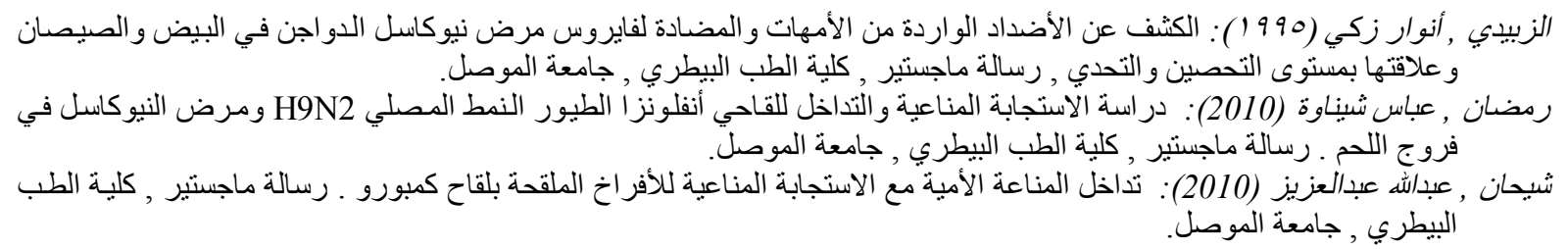

